\title{
On English Vocabulary Learning of Students with Learning Difficulties
}

\author{
Hong Li \\ School of Foreign Languages \\ Huanghe Science and Technology College \\ Zhengzhou, China
}

\begin{abstract}
Vocabulary learning is one of the most essential and fundamental elements in the study of English. However, there are always many kinds of problems in most students with learning difficulties. And it has caused many problems in English teaching. The present paper investigates the main problems in English vocabulary acquisition, such as the imprecise pronunciation, the ineffective way of learning vocabulary, the lack of self-confidence and so on. It also analyses the reasons involved. Then, it gives some corresponding and effective solutions.
\end{abstract}

Keywords-English vocabulary; vocabulary learning; students with learning difficulties

\section{INTRODUCTION}

\section{A. Research Background}

Many educators and teachers who teach foreign language all consider that vocabulary is the key element in foreign language learning. Linguist McCarthy pointed out that no matter how professional one's mastery of grammar is, without enough command of vocabulary, he will fail in communicating with others. As for English language, vocabulary is a powerful carrier of meaning and the fundamental factor of the language. Learners can manage to communicate in English by using the accumulative effect of individual words.

In China, English is one main subject. Students must learn English very hard to meet the need of all kinds of communication and examinations. In the process of learning, vocabulary learning, which is the foundation of English language learning, is the vital cell of the whole organism. It is the original element in cultivating the four basic skills of English listening, speaking, reading and writing of the learners.

\section{B. Motivations and Objectives}

In the process of English vocabulary learning, students with learning difficulties always meet many difficulties. The present paper contains a discussion of the problems involved. Imprecise pronunciation directly affects one's English level on a whole. To some extent, it will influence the learners' confidence and initiative in English vocabulary learning. At the same time, the great amount of English vocabulary and its lack of regularity also turn to be a reason for the lack of self-confidence of the learners. Meanwhile, the learners' way of learning English vocabulary is usually monotonous and boring. There is another problem, which is the influence of the regular forgetting system. This paper also investigates some possible solutions, of learning methods and detailed examples of how they may be carried out in practice and suggestions, such as precise pronunciations, more selfconfidence, and effective way of English vocabulary learning and overcoming the usual forgetting system.

\section{THE IMPORTANCE OF ENGLISH VOCABULARY LEARNING}

English is the most commonly used and most widely understood language. As a second language, English is often necessary for official business, education, information and other activities in a great many countries. It is one of the few "working" languages of the United Nations and is more frequently used than others. Therefore, the learning of English is magnificent for the further development of China. In English learning, vocabulary learning is one of the most important factors, because it is the key element of English language and the vital factor of communication in English, meanwhile, the learning of English vocabulary is a lifelong process.

\section{A. The Role of Vocabulary in English Language}

Vocabulary is one of the three most important elements of language. The quantity of one's vocabulary directly affects the development of his English listening, English speaking, English reading and English writing skills. Many famous teachers and educators have proved that vocabulary learning can accelerate the improvement of one's English level. The larger the learner's vocabulary scale, the higher his ability in English listening and reading. Although comprehension of the language is also influenced by relative background knowledge and reading strategies, the improvement of reading skills originally depends on the enlargement of vocabulary.

\section{B. The Role of Vocabulary in English Communication}

Vocabulary is the vital factor of communication in English language. Some beginners in learning this language at middle school level often manage to communicate in English by using the accumulative effect of individual words. 
According to the research of foreign authoritative agencies, if one's command of vocabulary is below 6,000, he will encounter great difficulties in English listening, speaking, reading and writing. The lack of vocabulary will be the biggest obstacle to English input and output, as well as affect the improvement of language ability directly. We all have such experience that if we don't know a key word, to understand the whole sentence may be impossible. On the contrary, even if we don't know grammatical knowledge and language background, but we can still guess the general idea of a sentence according to the vocabulary meaning. Therefore, vocabulary is the core.

\section{The Long-term Learning of English Vocabulary}

There is no doubt that English is one of the world's most widely used languages. English has become the language of international cooperation in science, technology, trade and transport. China has become one member of WTO. For the need of all kinds of international connections, English becomes much more important to China than ever before. Therefore, Chinese should learn English as a lifelong enterprise to meet all kinds of needs. Some researches related with vocabulary and vocabulary acquisition have improved that a certain language users will continue to enlarge his scope of vocabulary after growing up, so vocabulary learning is a continuous process.

\section{MAIN PROBLEMS IN ENGLISH VOCABULARY LEARNING}

\section{A. Problems in Pronunciation}

It is commonly existed among students with learning difficulties that they don't have right pronunciation. They always meet with great difficulties in pronouncing and don't have a clear idea about the regular pronunciation and stress of the vowels. This will affect English vocabulary learning. Some students refuse to answer questions in the class publicly, just for the fear of being laughed for their poor pronunciation. This will leave bad influence for both English learning and teaching. On the other hand, those who can't pronounce in the right way will not understand standard pronunciation. Some students lose confidence in English learning, just because they can't understand teachers' teaching and English materials while listening.

\section{B. The lack of self-confidence}

What makes most students with learning difficulties feel headache is to master English vocabulary and then to use them. Many students spend a great deal of time and energy in English vocabulary learning, but the studying is ineffective. As a result, they will not have enough command of words and phrases in writing, and they can do nothing more except quite simple greetings in oral communication. Then they will lose interest in studying and so as to lose confidence. After having tried several times, some students will think that they are not endowed with capacity in English learning. Therefore, they will lose confidence and be involved in self-abandonment. The result is the serious declining of English studying.

\section{The Ineffective Way in English Vocabulary Learning}

English vocabulary needs to be dealt with in systematical way in its own right. Vocabulary learners need to deal not only with single word lexical items, but also with longer multi-word items. Many students usually write down newly learned words in long lists in their files or exercise books. In many cases these lists are disorganized and often never be looked at again after they have been written. The students with learning difficulties usually can't record their newly learnt vocabulary in a more useful manner, which in return does little to help their progress.

\section{The Disturbance of Regular Forgetting System}

English vocabulary learning has close relationship with memory. Good memory will help English learners learn English vocabulary efficiently and improve English level quickly. But forgetting is also a passive factor which couldn't be avoided in the process of memorizing. No matter it is in the period of short-term memory, sensory memory or long-term memory, forgetting will happen at any time. Some words could be remembered after being forgotten, but some couldn't be remembered any more. After many researches Germany Psychologist got a curved line of forgetting, which showed the development of forgetting in the process of memorizing is a system commonly existing in human beings. The processing of forgetting is not balanced all the time. It is relatively quick at the first period of time and becomes slow afterward. No matter it is quick or slow, forgetting at different degree is impossible to be avoided. Forgetting may be the biggest obstacle in the process of English vocabulary learning.

\section{SOLUtions to THE PROBLEMS}

\section{A. Precise Pronunciation}

Students with learning difficulties should learn proper articulatory apparatus at first. The articulatory apparatus of a human being are contained in three important areas: the throat, the mouth, and the nose. For example, monogram -air and -are are read / $\mathrm{\epsilon} /$ in accent syllables, such as in the words chair, repair, care, hare; -igh is pronounced /ai/ in accent syllables, such as in the words high, bright light; -tch is read $/ \mathrm{t} \int /$ after vowels, such as in the words match, watch, catch; -tion is pronounced as $/ \int \mathrm{n} /$ or $/ \mathrm{t} \int \mathrm{n} /$, such in the words attention, condition, and question.

Pay more attention to the teachers' pronunciation teaching. Learn the right pronunciation and correct those with mistakes in time. Listen to English materials as usual as possible to cultivate accurate pronunciation and intonation. Rectify pronunciation through listening to international phonetic symbol or by other means. Listen more and try to imitate native speakers' pronunciation and intonation. Reading in the morning, expressing opinions in the class bravely and taking part in English activities are quite important. 


\section{B. More Self-confidence}

1) Self-confidence from precise pronunciation: As it is known to all that pronunciation is quite important in English vocabulary learning. If a student can have precise pronunciation in English, he will be brave enough to give response to a teacher's question and join in some classroom activities. This can also stimulate his interest in English learning. He will consider learning English as a comfortable and enjoyable thing.

2) Self-confidence from effective ways in vocabulary learning: It is said that perfect practice makes perfect. This golden saying means that proper way of doing something can be more effective and satisfying. If a student has his own effective way in English vocabulary learning, then he can make his work more efficient than other students without perfect practice. Effective ways can give the students more self-confidence.

3) Self-confidence from individual's attitude: Every English learner will meet all kinds of difficulties and obstacles in the process of English vocabulary learning. But the key problem is how to get rid of these difficulties and obstacles in an efficient way. If the students can remember two words every day, vocabulary will not be the first and foremost reason which makes them feel headache. For this reason, learners at middle school should show active and positive attitude towards the quantity of English vocabulary.

An active motivation can also do great contribution to English vocabulary learning. Psychologists have proved that interest can increase the effect of memory. It is the positive and long-last cognitive orientation. It accompanies with the exciting center of thinking activities in the brain layer. If the students become interested in English, they can tremendously improve the activeness, initiation and efficiency.

4) Self-confidence from well-organized vocabulary activities: In and out of classroom, students can join in some vocabulary activities to strengthen the effect of vocabulary learning. Well-organized activities can not only make English vocabulary learning more interesting but also help students of different levels get confidence during the process of playing games. Here are several vocabulary games, such as to use newly-learned words to make stories, to do or make word puzzles, to compete the speed of guessing one word through the definition or picture and so on.

5) Self-confidence from a teacher's encouragement: As Brown observes, "motivation is probably the most often used catch-all term for explaining the success or failure of virtually any complex task ", it is at the same time, according to Wall,[4] "perhaps the most obscure and difficult of all theoretical issues in general and educational psychology". Most psychologists would agree that a theory of human motivation concerns itself with "those factors that energize behavior and give it direction". It is also generally accepted that human motives to engage in a particular activity are based on underlying needs. It is also important, in addition to knowing why a person desires to engage in a particular activity, to know how strongly he desires to do so. In motivation research, therefore, tests are usually administered which measure not only the direction of the motivation but also motivational intensity. A teacher's encouragement can help the students learn with high emotion, which can promote the effect of English vocabulary learning.

\section{Efficient Way of Learning English Vocabulary}

1) English vocabulary learning in the context.: Words depend on context and are also influenced by the context. Only by getting the contextual meaning can we get clear and accurate comprehension. Without concrete context, any word, even if has been remembered, it still cannot be carried out in practice properly. Therefore, learners should try not to learn isolated English vocabulary but put the words in the context. Even though rote-reciting can enlarge the scope of vocabulary quickly, yet it is just a temporary way, which is not only boring, but also ineffective.

For the way of vocabulary learning, it is summarized in brief that the context will tell the readers the meaning of the vocabulary, for example: There is no place like home. Home in this sentence has the meaning of warm, sweet, comfort and so on. But if the context has the meaning of hating family life, then the word home will mean icy, make people vexed. So it can be said that the analyzing and understanding of the context have close relationship with comprehending the vocabulary precisely.

Reading is one of the valid methods to review those vocabularies having been learnt. When choosing reading materials, those too difficult or too easy are not appropriate. Choosing those materials which are suitable for one's own English level can not only improve one's reading ability, but also consoled those words which have been learnt. Along with the increasing of reading, a great deal of "passive vocabulary" can become "active". The original "nodding acquaintance" will become "intimate friend".

2) Methods of Word-formation: Affixation: The process by which words are formed by adding affixes to a root is called affixation. English affixation can be divided into prefixes and suffixes. Affixes that come before the root are called prefixes; those that come after the root are called suffixes. Some prefixes are more commonly used: un(unlike, unhappy, unusual) ; de-(decrease, decline,defuse); dis-(dislike, disagree). For the suffixes, when added to words, some of which can transform one word-class into another ( laugh - laughable, willing -willingness); others merely modify without converting (cartoon -cartoonist, starstarlet ). Some of the most productive suffixes which are commonly used are: -able (available, favorable); -er (learner; teacher, player); -y (sunny, cloudy, windy ); -ly ( badly, easily, bravely ).

a) Conversion: Conversion means using a form that represents one part of speech as another part of speech 
without changing the form of the word. In effect, a zero affix is added: for example, someone who knows he can say "The lights gleam in the night" with the word "gleam" as a verb, uses "gleam" as a noun in a sentence like "I can see a gleam in the night". So is in the following two sentences: "He is watering the flowers in the garden." and "I am thirsty. I need some water." In the first sentence, "water" is a verb, while in the second one, it is a noun.

b) Compoundin: Compounding is a process of wordformation by which two independent words are put together to make one word. Words formed by compounding are called compounds, for example, playground, classroom, blackboard, raincoat, storekeeper, and so on. If two words are put together, the meaning of the compounding word may have close relation with both of the two words. In the process of learning this kind of words, learners of middle school should think about the meaning of the two words together. This can make the learning of English vocabulary interesting and effective, not monotonous.

\section{3) The ways of linking in thinking}

a) Synonyms: Lexical items which have the same meaning but differ in morphemic structure, phonological form and usage are synonyms, and the relationship between them is one of synonyms. Synonyms can be said to occur if items are close enough in their meaning to allow a choice to be made between them in some contexts without affecting the sentence as a whole. Context plays an important part in deciding whether a set of lexical items is synonymous. For example, look and see, watch, observe can be synonyms, it can also be the synonym of seem appear in different context; the synonyms of good may be pleasant, kind, fine, nice in different context. According to this character, we should not find synonyms of one word isolated context, but put it into the sentences to check if they are synonyms or not. For example,

\section{Chinese food tastes good.}

Chinese food tastes nice.

In these two sentences, good and nice are synonyms, so they can exchange with each other in this situation.

b) Antonym: The term "antonym" is used for "oppositeness of meaning". Words that are in opposition are antonym, such as soft-hard, wide - narrow, alive-dead, male - female, buy — sell, give — receive, etc. Give is said to be the converse of receive, and vice versa: If A gives a book to $\mathrm{B}, \mathrm{B}$ receives a book from $\mathrm{A}$. In this way, we can memorize more English words with such connection.

c) Homographs: Words that have the same spelling form, but differ in sound and meaning are called homographs. For example, bow /bau/v. (bend the head or body in respect)-bow/bəu/ n. (a device for shooting arrows); lead /li:d/ v. (guide or direct)—lead/led / n. (a heavy ,soft, malleable, bluish-gray chemical element); permit /po'mit/ v. (to allow esp. by a formal written or spoken agreement, e. g. Will you permit us to leave now?) — permit / pə:mit/ (written statement giving one the right to do something, e. e. You can't work here without a work permit.)

d) Homophones: Words that have the same phonological form, but differ in spelling and meaning are called homophones, for example, air-heir, sea-see, hour-our. [8] Other examples can be found in the process of English vocabulary learning. Learners at middle school level should not just keep on learning, but should usually keep quiet to think if there is cut way to do the same thing. By the way of putting the homophones classification, mastering them will become easy and efficient.

e) Full homonyms: Word that are identical in sound and spelling but different in meaning are called full (or perfect ) homonyms, for example, back n. (the part of a person's body that is the side opposite the chest, and goes from the neck to the bottom of the spine or the tail, e. g. She was carrying the baby on the back.) - back adv. (in or into the place or position where someone or something was before, e. g. Put the book back on the shelf when you've finished.) — back adj. (at the back, e. g. the back wheel of a bicycle)-back v. (to support and encourage, often with money, e. g. The bank refused to back the scheme).

f) Series method: This method is to classify the English vocabulary into some systematical ones to learn, which is helpful to enlarge the scope of vocabulary quickly. Some words mean flowers, for example, lily, lotus, rose, violet, tulip, azalea, peony, and so on. Some mean fruits, for example, apple, pear, banana, cherry, orange and so on. Some mean birds, for example, sparrow, parrot, swallow, dove, woodpecker, and so on. Some mean transportation, for example, car, bike, bus, plane, ship, and so on. Some mean sports connected with ball, such as basketball, baseball, badminton, volleyball and football. Some are living beings' organs, such as head, arm, hand, leg, finger, hair and nose. Learners can classify them into different categories to promote the effect of vocabulary learning. Meanwhile, it can also generate the learners' interest and self-confidence in learning English.

\section{The Cultivating of a Good Memory System}

The cultivation of good memory should assure the quickness and long-last of memory on the precondition of precise memory. According to some famous psychologists, to review the knowledge after learning is not only necessary, but also effective, all for the reason of the curved line of forgetting. Therefore, how to arrange the review as well as when to do so becomes another important trachea.

It is commonly considered that we should arrange systematical reviewing step by step after learning, and review in time. To review in one to three days at the first period of time, then delude the times of reviewing as memory becomes more and more impregnable. The interval can also become longer.

The way of reviewing should be varied. We should change the way of reviewing continuously, for example, reviewing by oneself or by two students together, reciting, 
dictating, reading and so on. The change of reviewing way will make the brain avoid being exhausted, so as to make memory more effectively.

Setting a plan to learn a batch of vocabulary in a fixed period will do a lot of help in mastering and enlarging the scope of vocabulary. Students with learning difficulties can do in the following way: Make a plan to memorize a batch of vocabulary in a week, which will do great helps to the setting of a solid foundation for the afterward-English learning. However, the quantity and time to learn vocabulary should be appropriate, i. e. to review the learnt words again and again while sticking to learn new words. For example, after learning 30 new words in the first day, one better way is to review them when learning new words in the second day; in the third day, besides learning new words, students should also review those words learnt in the first and second day. Circulate in this way until the sixth or seventh day. This way aims to solve the problems of regular forgetting for English learners, so as to improve the effect of vocabulary memorizing.

\section{CONCLUSION}

Vocabulary is the key element of any language. In the process of English language learning, vocabulary learning is quite important. The capacity of using vocabulary directly affects the development of one's English listening, speaking, reading and writing skills. Learners often manage to communicate in English by using the accumulative effect of individual words. Students with English learning difficulties are usually at the starting line to learn English. So in order to have a solid command of English, students must learn English well.

However, there are many problems these students' English vocabulary learning. Firstly, at the beginning, they don't have precise pronunciation, which will affected not only the English vocabulary learning but also English speaking and listening. Secondly, There may be many words and phrases needed to be remembered. They always memorize, but forget at the same time. Gradually, students will meet with more and more difficulties. As a result, they will lose interest in studying, and eventually lose selfconfidence. Thirdly, the inputting of vocabulary is in lack of motion and sufficiency. It is also in need of techniques and strategies. English vocabulary is very important and needs to be dealt with systematically. These English learners always learn English vocabulary passively. At the same time, they don't know how to learn English efficiently. Fourthly, they usually have no way in avoiding the regular forgetting system.

The present paper investigates corresponding solutions to these problems. Firstly, cultivate right pronunciations through all kinds of ways to have a solid foundation of English learning. Secondly, take a positive attitude towards the importance and quantity of English vocabulary. Show an active motivation to learn vocabulary as an interesting process. Thirdly, find some more efficient ways in learning English vocabulary. Fourthly, overcome the regular forgetting system through efficient way of memorizing.

\section{REFERENCES}

[1] Pieter A. M. Seuren. (1978) Applied Linguistics and the Learning and Teaching Foreign Languages. London: Edward Arnold. 116-117,330.

[2] Scrivener. (2004) Learning Teaching: A Guidebook for English language teachers. Shanghai: Shanghai Foreign Language Education Press. 88.

[3] Brown. H. (1980) Principles of language learning and teaching, Englewood Cliffs, NJ. 112.

[4] Wall. W. (1958) The wish to learn: research into motivation, Educational Research. I. 23.

[5] Hilgard. E, R. Atkinson, R. Atkinson. (1979) Introduction to psychology. New York.280-343.

[6] J. A. Bright, G. P. McGregor, (1977) Teaching English as a Second Language. London: Longman Group LTD. 19.

[7] McCarthy, M. (1990) Vocabulary [M]. Oxford: OUP.

[8] Lu Guoqiang. (2005) Modern English Lexicology. Shanghai: Shanghai Foreign Language Education Press. 308-309, 334, 340342 . 